\title{
A Comparison of the Average Sitting Pressures and Symmetry Indexes between Air-adjustable and Foam Cushions
}

\author{
Won-Jin Kim ${ }^{1)}$, MoOnYOUNG CHANG ${ }^{2 *}$ \\ 1) Department of Rehabilitation Science, Inje University \\ 2) Department of Occupational Therapy, College of Biomedical Science and Engineering, Inje \\ University: 197 Inje Street, Gimhae, Gyengsangnam-do 621-749, Republic of Korea. \\ TEL: +82 55-320-3685, FAX: +82 55-326-4885
}

\begin{abstract}
Purpose] The purpose of this study was to determine the best adjustable cushions, for the maintenance of normal sitting balance by healthy persons in wheelchairs, from a foam cushion, and a newly-developed air-adjustable cushion. [Subjects] Eighteen healthy participants ( 9 men, 9 women) were recruited. [Methods] Participants were evaluated using the Force Sensing Array System to assess average sitting pressure and the symmetry index of chair sitting under the following conditions: no seat cushion, a foam cushion, and a newly-developed air-adjustable cushion. [Results] The results show that there were no significant differences among the average sitting pressures which were measured on the hard surface of a chair, a foam cushion, and the newly-developed cushion. The airadjustable cushion's symmetry index turned out to be closer to 0 than those of the foam cushion and the hard surface of the chair. [Conclusion] We suggest that the newly-developed air-adjustable cushion contributes to a more symmetrical sitting posture than the basic foam cushion or no seat cushion.

Key words: Cushions, Seat pressure, Symmetry index
\end{abstract}

(This article was submitted Apr. 9, 2013, and was accepted May 4, 2013)

\section{INTRODUCTION}

Because the population is aging, the number of disabled people is continually increasing. The number of people in South Korea with disabilities has been estimated to be $2,520,000$ people. Of these, 1,340,000 (53.1\%) were reported to be physically disabled, and 260,000 (10.4\%) had a neurological disorder in 2010 . Thus, there are many wheelchair users, and because of the natural aging of the population, this number will increase in the future ${ }^{1)}$.

Korean wheelchair services for disabled persons do not reflect the characteristics of patients' physical handicaps, whereas patients require services that are tailored to their needs. As a result, many cases have emerged in which wheelchair users have developed various kinds of secondary complications or aggravated symptoms ${ }^{2}$.

Disabled people require more postural support than a common chair or wheelchair provides. To achieve this, the wheelchairs and chairs used by disabled persons require modification or a specially designed seating system ${ }^{3}$. A seat cushion provides benefits well beyond comfort, including pressure management and positioning that can reduce fatigue and enhance seated balance throughout the day.

Wheelchair seat cushions are generally filled with water, foam, gel, or air. Recently the frequency of use of a combi-

${ }^{*}$ To whom correspondence should be addressed.

E-mail: myot@inje.ac.kr nation of materials has been increasing. The seat pressure characteristics of wheelchair seat cushions have been found to be best in terms of the materials used. Air, gel, and foam, in that order, provide superior seat pressure characteristics in wheelchair seat cushions ${ }^{4)}$. However, Rosenthal ${ }^{5)}$ reported that the seat pressure of air cushions is worse than that of gel or polymer foam cushions, and that the quality varies among different products.

Some researchers have compared and analyzed many variables related to cushion contact pressure, but there have been no clear findings as to what the best material for seat cushions is ${ }^{6,7)}$. It is necessary to develop new products, and further research is needed to assess the seat pressure characteristics of wheelchair seat cushions. Accordingly, this study developed an air-adjustable seat cushion filled with foam, and then compared its sitting pressure characteristics with a commonly used foam cushion and the hard surface of a chair.

\section{SUBJECTS AND METHODS}

The study subjects were 18 healthy persons ( 9 men, 9 women) aged $20-32$ years ( $7 \pm 3.6$ years). The averages of their heights and weights were $170.0 \pm 7.1 \mathrm{~cm}$ and $62.7 \pm$ $11.9 \mathrm{~kg}$, respectively. None of the subjects suffered from any neurological or orthopedic disorder that might have interfered with the goals of the research. All subjects read and signed an informed consent form, which was approved by Inje University Ethics Committee for Human Investiga- 
tions, prior to their participation.

Force Sensing Array (FSA) System 4.0 software (Vista Medical, 120 Maryland Street, Winnipeg, Manitoba R3G 1L1, Canada) was used to assess the participants' symmetry and the average sitting pressure. The FSA system comprises a pressure-sensing mat $(48 \times 48 \mathrm{~cm})$ containing 256 sensors connected to a computer through an interface module. The acquisition frequency was set to $5 \mathrm{~Hz}$. The designated software was used to calibrate the system in $20 \mathrm{mmHg}$ intervals to a maximum of $200 \mathrm{mmHg}^{8}$. Data computed from the sensors are presented in a color-coded contour map with numerical pressure values. The contour map visually displays the pressure distribution on the seat, and each map is accompanied with numerical values, including average pressure (the mean of the sensor values) and maximum pressure. The symmetry index was used to assess the differences in pressure distribution during sitting. In order to measure the pressure distribution for the left and right hip, the bilateral $9 \times 9(13.5 \times 13.5 \mathrm{~cm})$ pressure transducer data from the area of the ischial tuberosity were processed. The symmetry index formula is shown as follows 9,10 ).

Symmetry Index $(\%)=$ [Variables (Lt. side)-Variables (Rt. side)/Variables (Lt. side) + Variables (Rt. Side)] $\times 2 \times 100$

All participants were evaluated on the same chair and were randomly assessed on this chair using the following conditions: no seat cushion (hard chair), a foam cushion, and the newly-developed air cushion. To fulfill the research purpose, this study used a basic chair with a floor-to-seat height of $50 \mathrm{~cm}$, seat depth of $40 \mathrm{~cm}$, and seat width of $46 \mathrm{~cm}$. The newly-developed air cushion (OK Meditech, Korea) is made from urethane and has small air holes so that air can move in and out of the cushion. Urethane foam functions as a filler, so that when subjects sit down, the air moves out of the cushion and the shape of the cushion changes to suit the subject's body. The foam cushion used in this experiment was made of polyurethane, which is a common material.

When sitting on the hard surface of the chair, users sat in a relaxed position with the hip joint, knee joint, and ankle joint flexed at 90 degrees; the foothold height was adjusted to accomplish this. The subjects' hands were positioned on their thighs.

Once they were seated on the chair, we asked subjects to keep looking forward and not to move after the FSA mat flat on a chair placed. We measured the pressure between the surface and participants' bodies for 70 seconds ${ }^{6)}$. We discarded the first and last 5 seconds, keeping the middle 60 seconds of data for the analysis. The data were analyzed using SPSS version 17.0. Kruskal-Wallis $\mathrm{H}$ verification was employed to analyze the differences among the average sitting pressures and symmetry indexes.

\section{RESULTS}

Our analysis showed that there were no significant difference among the average sitting pressures, which were $62.50 \mathrm{mmHg}, 61.92 \mathrm{mmHg}$, and $60.95 \mathrm{mmHg}$ for the hard surface chair, the foam cushion, and the newly-developed air-adjustable cushion, respectively ( $\mathrm{p}>0.05)$. The symmetry index was $23.45 \%$ for the foam cushion, $7.44 \%$ for the hard surface cushion, and $5.80 \%$ for the newly-developed air cushion. Thus, the newly-developed air cushion's symmetry index was closer to 0 than those of the foam cushion and the hard surface of the chair $(\mathrm{p}<0.05)$ (Table 1$)$.

\section{DISCUSSION}

Recently, the number of wheelchair patients has increased, but there are many cases where an unsuitable wheelchair causes difficulties for users, and this problem has been not yet been solved ${ }^{2,11)}$. According to Thyberg's research $^{12)}, 87 \%$ of wheelchair patients responded that the seating system is the most important element of a wheelchair, and the need for customized wheelchair seats is also increasing. Ready-made seats are cheap, but pose difficulties when it comes to meeting every client's physical needs. On the other hand, while customized seat cushions are tailored to each individual, they are costly. Moreover, customized seats do not adjust to users' growth, weight fluctuation, deformity, or clothing, and clients might need to repurchase the product in the future. Wheelchair users require cheap, customized seats that can be adjusted to suit their clothing and any change in physique. Thus, we developed a customized seat cushion, which can be adjusted by air pressure, and compared its pressure characteristics with those of other support surfaces so that customers can choose appropriately.

According to our analysis, there were no identifiable differences among the average sitting pressures, but the symmetry index of the newly-developed air cushion, which can be controlled by air pressure, was close to 0 . The range of the symmetry index is from 0 to 100 , and a symmetry index of 0 means the pressures on both sides of the body are the same. High symmetry index values indicate that there is a large pressure difference between the left and the right ${ }^{9}$. In this study, the newly-developed air cushion exhibited a lower symmetry index than the hard surface of the chair. This result occurred because the newly-developed air cushion could control air pressure and hardens after sitting to suit the user's body.

Table 1. Comparison of the average sitting pressures and symmetry indices according to the sitting surface

\begin{tabular}{lccc}
\hline & Chair sitting & Foam cushion & $\begin{array}{c}\text { Newly-developed } \\
\text { air cushion }\end{array}$ \\
\hline Average sitting pressure $(\mathrm{mm} \mathrm{Hg})$ & $62.50 \pm 4.33$ & $61.92 \pm 4.90$ & $60.95 \pm 5.93$ \\
Symmetry index $(\%)^{*}$ & $7.44 \pm 5.28$ & $23.45 \pm 22.14$ & $5.80 \pm 4.68$ \\
\hline$* \mathrm{p}<0.05$ & & &
\end{tabular}


$\mathrm{Rhee}^{13)}$ reported that it is better to use a padded seat if possible, because if a wheelchair seat is too soft, lateral inclination of the pelvis may occur. In addition, Park et al. ${ }^{14)}$ remarked that a hard surface chair supports a symmetrical pose. Cushions should be designed based on comfort, and need to promote proper position and balance for each individual, aiming to lower the probability of pressure ulcers $^{15,16)}$. Among the seat cushion evaluation factors related to the development of pressure ulcers, interface pressure is most relevant ${ }^{17)}$. Thus, in this study, we evaluated average sitting pressure, and the result for each type of seat surface was greater than $60 \mathrm{mmHg}$. The sitting pressure of the newly-developed air cushion was the lowest. The probability of pressure ulcers is known to rise at values of more than $60 \mathrm{mmHg}$ of pressure, but there are no clear standards for reducing the pressure to avoid pressure ulcers ${ }^{17}$.

There are some examples of the application of draft design using a conventional stress measurement method for seat cushions that are curved on the bottom ${ }^{18)}$. However, these products are not yet available on the market. Therefore, studies of customized seat cushions are expected to provide users with better option. However, since this research did not target real wheelchair users, it needs to be compared with analyses of disabled and healthy persons' use of wheelchair seating.

\section{ACKNOWLEDGEMENT}

This work was supported by the 2013 Inje University research grant.

\section{REFERENCES}

1) Korea National Statistical Office: Registered Disabled Persons. 2010.

2) Koo HM, Jeong DH, Kong JY, et al.: A study on the using realities and satisfaction of the wheelchair of the disabled. Journal of special education theory and practice, 2005, 6: 229-245.

3) Kong JY, An NY: Effect of wedge height of inner on seated pressures. J Spec Educ Rehabil Sci, 2009, 48: 101-118.

4) Shaw CG: Retention of supportive properties by eggcrate and form wheelchair cushion. J Rehabil Res Dev, 1998, 35: 396-404. [Medline]

5) Rosenthal MJ: A wheelchair cushion designed to redistribute sites of sitting pressure. Arch Phys Med Rehabil, 1996, 77: 278-282. [Medline] [CrossRef]

6) Ferrarin M, Andreoni G, Pedotti A: Comparative biomechanical evaluation of different wheelchair seat cushions. J Rehabil Res Dev, 2000, 37: 315-324. [Medline]

7) Gil-Agudo A, Pena-Gonzalez A, Ama-Espinosa A, et al.: Comparative study of pressure distribution at the user-cushion interface with different cushions in a population with spinal cord injury. Clin Biomech (Bristol, Avon), 2009, 24: 551-557. [Medline] [CrossRef]

8) Lee IH, Park SY: Assistive cushions for symmetric wheelchair sitting by stroke patients. J Phys Ther Sci, 2011, 23: 837-840. [CrossRef]

9) Chen $\mathrm{CH}$, Lin $\mathrm{KH}, \mathrm{Lu} \mathrm{TW}$, et al.: Immediate effect of lateral-wedged insole on stance and ambulation after stroke. Am J Phys Med Rehabil, 2010, 89: 48-55. [Medline] [CrossRef]

10) Hesse S, Reiter F, Jahnke M, et al.: Asymmetry of gait initiation in hemiparetic stroke subjects. Arch Phys Med Rehabil, 1997, 78: 719-724. [Medline] [CrossRef]

11) Simmons SF, Schnelle JF, Macrae PG, et al.: Predictors of wheelchair activity in nonambulatory nursing home residents. J Am Geriatr Soc, 1995, 43: 384-388. [Medline]

12) Samuelsson $K$, Larsson $H$, Thyberg $M$, et al.: Wheelchair seating intervention. Results from a client-centered approach. Disabil Rehabil, 2001, 23: 677-682. [Medline] [CrossRef]

13) Rhee KM: The effective strategies for improving seating and positioning for persons with wheelchair user. J Phys Multi Disabil, 2001, 37: 61-77.

14) Park SY, Lee IH, Jeon CB, et al.: Comparison of the sitting pressure of stroke patients according to seat shapes. 2010 Fall Conference of Ergonomics Society of Korea, 2010, 10: 15-19.

15) Sprigle S, Chung KC, Brubaker CE: Factors affecting seat contour characteristics. J Rehabil Res Dev, 1990, 27: 127-134. [Medline] [CrossRef]

16) Yuen HK, Garrett D: Comparison of three wheelchair cushions for effectiveness of pressure relief. Am J Occup Ther, 2001, 55: 470-475. [Medline] [CrossRef]

17) Conine TA, Hershler C, Daechsel D: Pressure ulcer prophylaxis in elderly patients using polyurethane foam or Jay wheelchair cushions. Int J Rehabil Res, 1994, 17: 123-137. [Medline] [CrossRef]

18) Tanimoto $Y$, Takechi H, Nagahata H, et al.: The study of pressure distribution in sitting position on cushions for patient with SCI (Spinal Cord Injury). Instrumentation and Measurement. IEEE Trans, 1998, 47: 1239-1243. 